\title{
Cost-Effectiveness Analysis of the Adjunctive Therapy of Ivabradine for the Treatment of Heart Failure with Reduced Ejection Fraction
}

This article was published in the following Dove Press journal: ClinicoEconomics and Outcomes Research

\author{
Rungroj Krittayaphong' \\ Jirawit Yadee ${ }^{2}$ \\ Unchalee Permsuwan (D) ${ }^{2}$ \\ 'Division of Cardiology, Department of \\ Medicine, Faculty of Medicine Siriraj \\ Hospital, Mahidol University, Bangkok, \\ Thailand; ${ }^{2}$ Department of Pharmaceutical \\ Care, Faculty of Pharmacy, Chiang Mai \\ University, Chiang Mai, Thailand
}

Background: The benefit of ivabradine as an adjunctive therapy to conventional treatment in patients with heart failure (HF) with reduced ejection fraction (HFrEF) is a reduction in both cardiovascular death and HF hospitalization. This study aimed to analyze the costeffectiveness of ivabradine plus standard treatment compared with standard treatment alone. Methods and results: An analytical decision model was used to analyze lifetime costs and quality-adjusted life-years (QALYs) from a healthcare perspective. The study cohort comprised HFrEF patients with left ventricular ejection fraction (LVEF) $<35 \%$, with subgroup analysis of those with baseline heart rate $\geq 77 \mathrm{bpm}$. Clinical inputs were obtained from a landmark trial. All cost-related data, risk of non-cardiovascular death and readmission rate were based on Thai data. Costs and QALYs were discounted at 3\% and presented as 2018 values. Findings were reported as incremental cost-effectiveness ratios (ICERs). Sensitivity analyses were also performed. Ivabradine plus standard treatment costs more than standard treatment ( 71,071 vs 18,736 THB or $2,161.54$ vs 569.82 USD), and is more effective (6.08 QALYs vs 5.84 QALYs), yielding an ICER of 214,219 THB/QALY (6,515.16 USD/QALY). Ivabradine was not cost-effective at the Thai willingness to pay threshold of 160,000 THB/ QALY. The results were sensitive to risk of non-hospitalization cardiovascular death, and costs of HF hospitalization and ivabradine. However, the ICER of subgroup was below the threshold (86,317 THB/QALY or 2,625.20 USD/QALY).

Conclusion: This study revealed the addition of ivabradine to standard treatment to be a cost-effective treatment strategy in HFrEF patients with a heart rate $\geq 77 \mathrm{bpm}$.

Keywords: ivabradine, cost-effectiveness, heart failure with reduced ejection fraction, heart rate, Thailand

\section{Introduction}

Ivabradine has been recommended as an adjunctive therapy to conventional treatment in patients with heart failure (HF) with reduced ejection fraction (HFrEF), sinus rhythm, and heart rate greater than 70 beats per minute (BPM). Conventional treatments for patients with this condition include angiotensin-converting enzyme inhibitors (ACEIs) or angiotensin receptor blockers (ARBs), beta-blockers, and mineralocorticoid receptor antagonists (MRAs). The recommendation for ivabradine is class IIa in the current practice guidelines from the European Society of Cardiology (ESC) ${ }^{1}$ and the American College of Cardiology (ACC). ${ }^{2}$ Class IIa means that the treatment should be considered in selected population in order to reduce cardiovascular death and heart failure hospitalization based on the findings
Correspondence: Unchalee Permsuwan Department of Pharmaceutical Care, Faculty of Pharmacy, Chiang Mai

University, Suthep Road, Muang District, Chiang Mai 50200, Thailand

Tel +66 89-635-9268; +66 5-394-435I

Fax +66 5-322-274I

Email unchalee.permsuwan@gmail.com 
and recommendations of the Systolic Heart failure treatment with the $I_{\mathrm{f}}$ inhibitor ivabradine Trial (SHIFT) study. ${ }^{3}$

Ivabradine is a selective $I_{\mathrm{f}}$ channel blocker that inhibits the pacemaker current of the sinoatrial node cells, which results in a reduced heart rate with no lowering of blood pressure, no modification of cardiac contractility, and no adverse influence on sympathetic system modulation. ${ }^{4}$ Since elevated heart rate increases the risk of death and adverse outcomes in patients with $\mathrm{HFrEF}^{5,6}$ the reduction of heart rate is associated with a better patient outcomes. ${ }^{3,7}$ In the SHIFT study, in patients with HFrEF with left ventricular ejection fraction (LVEF) less than $35 \%$ and on conventional treatment for HFrEF, the addition of ivabradine $7.5 \mathrm{mg}$ twice a day was found to be associated with a substantial reduction in the primary composite endpoints "cardiovascular (CV) death" and "HF hospitalization". 3

Since healthcare resources are limited in all countries, the recommendations for medications, especially costly medications, may require country-specific evidence that supports the cost-effectiveness of the drug being requested. To justify the cost-effectiveness of new interventions, the incremental costeffectiveness ratio (ICER) is commonly compared with the level of willingness to pay (WTP). Although there have been several published cost-effectiveness studies of ivabradine in patients with HF from the United States, ${ }^{8}$ European countries ${ }^{8,9}$ and Australia, ${ }^{10}$ those countries have different healthcare systems and a higher level of WTP compared to Thailand, which is classified as a middle-income country. Accordingly, the aim of this study was to analyze the costeffectiveness of ivabradine plus standard treatment compared with standard treatment alone in Thai patients with HFrEF.

\section{Methods}

\section{Model Description}

A previously used and reported analytical decision model for HFrEF treatment ${ }^{11}$ was applied in the present study (Figure 1). Briefly, during each 3-month cycle of a patient's lifetime, patients with HFrEF would be alive with no events, would be hospitalized when HF symptoms occurred, or would be dead from either cardiovascular causes (CV death) or non-CV causes (non-CV death). For hospitalization health state, HFrEF patients were either readmitted or not readmitted within 30 days of discharge. The model assumed that only patients with a 30-day readmission could die from CV causes. The costeffectiveness of ivabradine was estimated based on the incremental cost per QALY gained. The data analysis using
Microsoft ${ }^{\circledR}$ Excel (Microsoft Corporation, Redmond, WA, USA) was performed from a healthcare system perspective.

\section{Cohort and Subgroup Populations}

The baseline characteristics of the cohort population in this study (HFrEF patients with LVEF less than 35\% receiving conventional pharmacologic HFrEF treatment) were the same as those evaluated and reported in the SHIFT trial. ${ }^{3}$ The cohort population in this study was aged $\geq 60$ years according to the reported average age of Thai patients with HF. ${ }^{13}$ Included patients with a heart rate $\geq 77 \mathrm{bpm}$ were included in the subgroup analysis.

\section{Intervention and Comparator}

Ivabradine ( $7.5 \mathrm{mg}$ twice daily) added to the standard treatment was compared with standard treatment alone. Standard treatment included the medications listed in the SHIFT trial, ${ }^{3}$ including $\beta$ blockers (90\%), ACE inhibitors (80\%), ARBs $(14 \%)$, and diuretic drugs (60\%). Only the most commonly used medication in each drug group was taken into consideration according to the recommendation of the Thai Health Technology Assessment (HTA) guideline. ${ }^{12}$ Those medications included carvedilol (6.25 $\mathrm{mg}$ twice daily), enalapril (10 mg twice daily), losartan (50 mg once daily), and spironolactone (25 mg once daily).

\section{Input Parameters Cardiovascular Mortality Cohort Population}

The CV mortality risks were derived from the 22.9-month follow-up period in the SHIFT trial, ${ }^{3}$ which reported 491 (15.04\%) CV deaths out of 3264 patients receiving standard treatment, and 449 (13.85\%) CV deaths out of 3241 patients receiving ivabradine plus standard treatment. The risks were then converted to 3-month probabilities. Based on information from a Thai database, ${ }^{13} 15 \%$ of all $\mathrm{CV}$ deaths in patients with HF occurred during the hospitalization, so this proportion was used to calculate the hospitalization and non-hospitalization mortality risks. The hospitalization and non-hospitalization mortality risk in patients receiving standard treatment were 0.0032 and 0.0179 , respectively; whereas, the hospitalization and nonhospitalization mortality risk in the ivabradine group were 0.0029 and 0.0164 , respectively (Table 1 ).

\section{Subgroup Population}

Although significant reduction in $\mathrm{CV}$ mortality was not demonstrated in the main SHIFT trial, which enrolled 


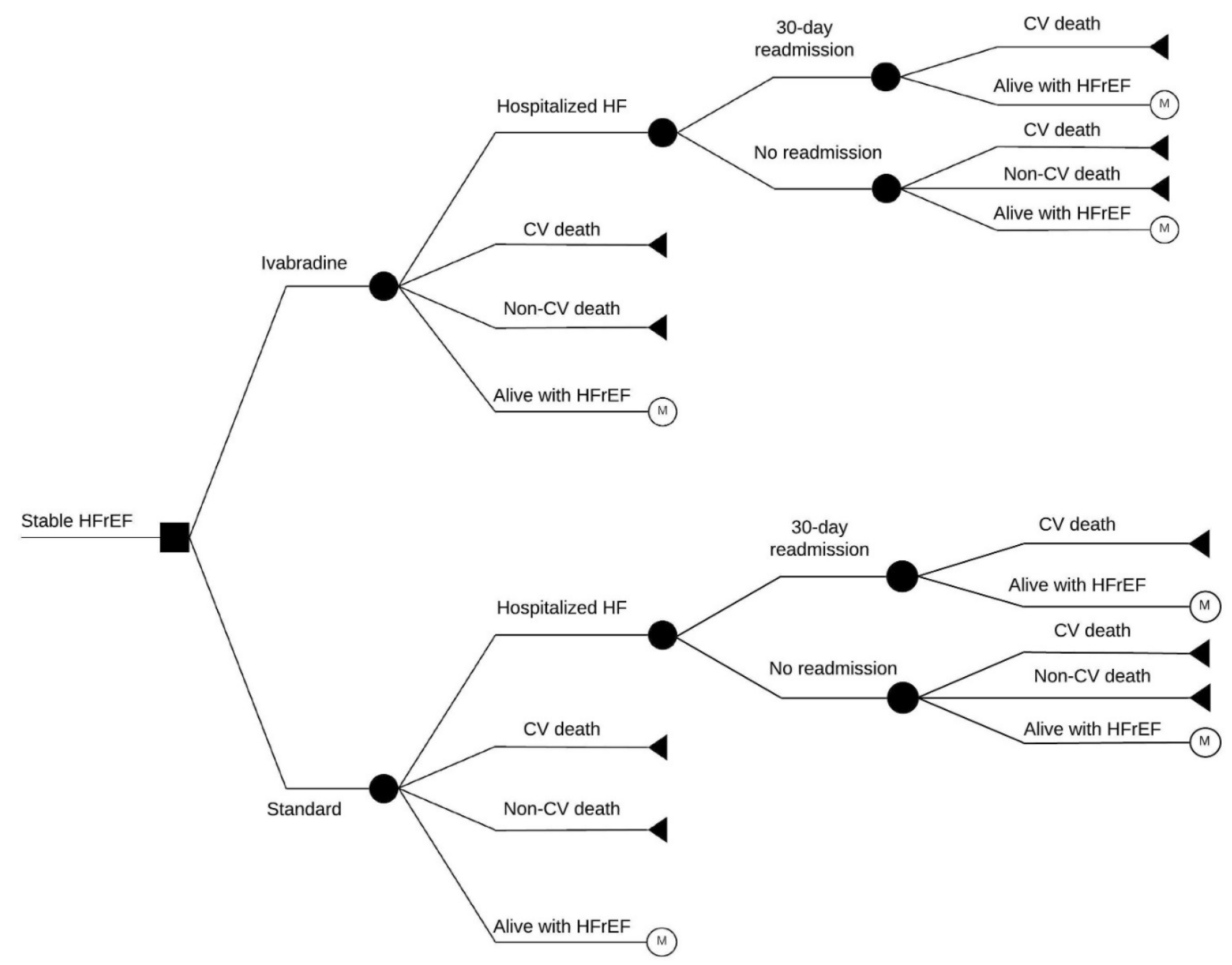

Figure I Analytical decision model.

Abbreviations: $\mathrm{CV}$, cardiovascular; $\mathrm{HF}$, heart failure; HFrEF, heart failure with reduced ejection fraction.

patients with HFrEF and sub-analyzed patients with a baseline heart rate $>70 \mathrm{bpm}$, a significant reduction in $\mathrm{CV}$ mortality was observed in HFrEF patients with baseline heart rate $\geq 77 \mathrm{bpm}$ that were treated with ivabradine plus standard treatment (hazard ratio [HR]: 0.81, 95\% confidence interval [CI]: $0.69-0.96) .{ }^{14}$ We calculated the CV mortality risk in this subgroup using the following steps. First, we calculated the relative risk (RR) of the composite primary outcome (cardiovascular death or hospital admission between patients with a baseline heart rate of $\geq 77 \mathrm{bpm}$ and patients with a baseline heart rate of $<77 \mathrm{bpm}$ in the standard treatment group), which yielded a RR of $1.53[\mathrm{RR}=(581 /$ $3357) /(356 / 3144)]$. Second, the number of CV deaths in patients with a baseline heart rate of $\geq 77 \mathrm{bpm}$ was estimated from the overall number of CV deaths (491 deaths) in the standard treatment group and the calculated RR from the first step, which resulted in 297 deaths $(491 * 153 / 253)$ out of
1700 patients who were receiving the standard treatment within the 22.9-month follow-up period. To estimate the number of $\mathrm{CV}$ deaths in the ivabradine plus standard treatment group, the aforementioned HR of 0.81 was used. Next, the $\mathrm{CV}$ mortality risk for a 3-month cycle was calculated using the same method as the one used for the cohort population. The 3-month risk of $\mathrm{CV}$ mortality in patients with a baseline HR of $\geq 77 \mathrm{bpm}$ in the standard treatment group and the ivabradine plus standard treatment group was 0.0248 and 0.0202 , respectively (Table 1$)$.

\section{Non-Cardiovascular Mortality}

Age-specific mortality rates for Thai general population that died from a non-CV cause were calculated based on data from the burden of disease in the Thai population, ${ }^{15}$ and from the cause of death on record at the Thailand Ministry of Public Health. ${ }^{16}$ These mortality rates were then converted to 3-month risks (Table 1). 
Table I Clinical Input Parameters

\begin{tabular}{|c|c|c|c|}
\hline Parameters & Value & Range & References \\
\hline $\begin{array}{l}\text { Risk of CV mortality } \\
\text { Standard }{ }^{\text {a }} \\
\text { Ivabradine }^{\text {b }} \\
\text { Annual CV mortality rate from hospitalization }\end{array}$ & $\begin{array}{l}0.0211 \\
0.0193 \\
0.15\end{array}$ & $\begin{array}{l}0.0183-0.0211 \\
0.0166-0.0220\end{array}$ & $\begin{array}{l}\text { Swedberg, et } \mathrm{al}^{3} \\
\text { Swedberg, et } \mathrm{al}^{3} \\
\text { Thailand database }\end{array}$ \\
\hline $\begin{array}{l}\text { Risk of CV mortality from hospitalization } \\
\text { Standard } \\
\text { Ivabradine }^{\mathrm{d}}\end{array}$ & $\begin{array}{l}0.0032 \\
0.0029\end{array}$ & $\begin{array}{l}0.0022-0.0042 \\
0.0020-0.0038\end{array}$ & $\begin{array}{l}\text { Calculation } \\
\text { Calculation }\end{array}$ \\
\hline $\begin{array}{l}\text { Risk of CV mortality from non-hospitalization } \\
\text { Standard } \\
\text { Ivabradine }^{f}\end{array}$ & $\begin{array}{l}0.0179 \\
0.0164\end{array}$ & $\begin{array}{l}0.0154-0.0204 \\
0.0140-0.0188\end{array}$ & $\begin{array}{l}\text { Calculation } \\
\text { Calculation }\end{array}$ \\
\hline $\begin{array}{l}\text { Risk of CV mortality (subgroup population with baseline HR } \geq 77 \\
\text { bpm) } \\
\text { Standard } \\
\text { Ivabradine }^{\text {h }}\end{array}$ & $\begin{array}{l}0.0248 \\
0.0202\end{array}$ & $\begin{array}{l}0.0205-0.0291 \\
0.0163-0.0241\end{array}$ & $\begin{array}{l}\text { Calculation } \\
\text { Calculation }\end{array}$ \\
\hline $\begin{array}{l}\text { Risk of non-CV mortality by age } \geq 60 \text { years } \\
60 \\
65 \\
70 \\
75 \\
80 \\
\geq 85\end{array}$ & $\begin{array}{l}0.0035 \\
0.0053 \\
0.0080 \\
0.0128 \\
0.0203 \\
0.0357\end{array}$ & & $\begin{array}{l}\text { Burden of disease in Thai } \\
\text { population, }{ }^{15} \text { Health statistics }\end{array}$ \\
\hline $\begin{array}{l}\text { Risk of HF hospitalization } \\
\text { Standard } \\
\text { Ivabradine }\end{array}$ & $\begin{array}{l}0.0297 \\
0.0224\end{array}$ & $\begin{array}{l}0.0263-0.0331 \\
0.0195-0.0253\end{array}$ & $\begin{array}{l}\text { Swedberg, et al }{ }^{3} \\
\text { Swedberg, et } \mathrm{al}^{3}\end{array}$ \\
\hline $\begin{array}{l}\text { Risk of all-cause } 30 \text {-day readmission } \\
\text { Risk of all-cause } 30 \text {-day readmission for standard } \\
\text { Relative risk of all-cause } 30 \text {-day readmission ivabradine vs standard } \\
\text { Risk of all-cause } 30 \text {-day readmission for ivabradine }{ }^{k}\end{array}$ & $\begin{array}{l}0.2882 \\
0.833 \\
0.2401\end{array}$ & $\begin{array}{l}0.2594-0.3171 \\
0.669-1.014\end{array}$ & $\begin{array}{l}\text { Thailand database }{ }^{13} \\
\text { Komajda, et al } \\
\text { Calculation }\end{array}$ \\
\hline
\end{tabular}

Notes: ${ }^{2} 3$-month rate $=-[\ln (1-15.04 \%)] /(22.9 / 3)=0.0214$. Then 3-month probability $=1-\exp (-0.0214)=0.021 \mathrm{I}$. ${ }^{\mathrm{b}} 3$-month rate $=-[\ln (1-13.85 \%)] /(22.9 / 3)=0.0195$. Then 3-month probability $=1-\exp (-0.0195)=0.0193 .{ }^{c} \mathrm{I}$-year $\mathrm{CV}$ mortality rate $=0.0214 \times(12 / 3)=8.54 \%$. Of those $8.54 \%, 15 \%$ died from hospitalization; therefore, $\mathrm{I}$-year CV hospitalization mortality rate $=15 \% \times 8.54 \%=1.28 \%$. Risk of CV mortality from hospitalization for 3 months $=\mathrm{I}-\exp (-\mathrm{I} .8 \% \times(3 / \mathrm{I} 2))=0.0032$. $\mathrm{d}_{\mathrm{I}}$-year $\mathrm{CV}$ mortality rate $=0.0195 \times(12 / 3)=7.81 \%$. Of those $7.81 \%, 15 \%$ died from hospitalization; therefore, 1 -year CV hospitalization mortality rate $=15 \% \times 7.81 \%=1.17 \%$. Risk of $\mathrm{CV}$ mortality from hospitalization for 3-month period $=1-\exp (-1.17 \% \times(3 / 12))=0.0029$. ${ }^{\text {e}}$ Risk of CV mortality from non-hospitalization for 3-month period $=$ $0.02 \mathrm{II}-0.0032=0.0179$. ${ }^{\mathrm{f}}$ Risk of CV mortality from non-hospitalization for 3-month period $=0.0193-0.0029=0.0164 .{ }^{8}$ Risk of $\mathrm{CV}$ mortality among ivabradine group with baseline $\mathrm{HR} \geq 77 \mathrm{bpm}\left(3-\right.$ month rate) $=-[\ln (1-17.47 \%)] /(22.9 / 3)=0.025 \mathrm{I}$. Then 3-month probability $=1-\exp (-0.025 \mathrm{I})=0.0248$. ${ }^{\mathrm{h}}$ Risk of $\mathrm{CV}$ mortality among ivabradine group with baseline $H R \geq 77 \mathrm{bpm}=0.025 \mathrm{I} \times 0.8 \mathrm{I}=0.0204$. Then 3-month probability $=1-\exp (-0.0204)=0.0202$. $^{\mathrm{i}}$ Risk of all-cause 30-day readmission for standard treatment $=I-\exp (-34 \%)=0.2882$. The $34 \%$ rate of readmission was obtained from the Thai heart failure national database. ${ }^{i}$ Relative risk $=0.78 /[(I-0.2882)+(0.2882 \times$ $0.78)]=0.833$. ${ }^{k}$ Risk of all-cause 30-day readmission for sacubitril-valsartan $=0.2882 \times 0.833=0.240 \mathrm{I}$.

Abbreviations: bpm, beats per minute; $\mathrm{CV}$, cardiovascular; $\mathrm{HF}$, heart failure; $\mathrm{HR}$, heart rate.

\section{Hospitalization and All-Cause Readmission}

The risk of HF hospitalization was derived from the data reported in the SHIFT trial. ${ }^{3}$ At a median follow-up of 22.9 months, $672(20.59 \%)$ out of 3264 patients receiving the standard treatment were hospitalized, whereas 514 (15.86\%) out of 3241 patients receiving ivabradine plus the standard treatment were hospitalized. The 3-month risk of HF hospitalization for the standard group and the ivabradine group was 0.0297 and 0.0224 , respectively (Table 1 ).
The rate of readmission from any cause within 30 days in the standard treatment group was estimated from the Thai HF national database, ${ }^{13}$ which reported a $34 \%$ rate of readmission. To derive the all-cause readmission rate in the ivabradine group, we used data from the post-hoc analysis of the SHIFT trial (odds ratio [OR]: 0.78 ; $95 \%$ CI: $0.59-1.02),{ }^{17}$ and this data were converted to relative risk (RR). The risk of readmission in the ivabradine group was the product of the RR of 
Table 2 Costs and Utility Parameters

\begin{tabular}{|l|l|l|l|}
\hline Parameters & Value & Range & References \\
\hline $\begin{array}{l}\text { Costs (THB) } \\
\text { Medications (3 months) }\end{array}$ & & & \\
$\quad$ Standard & 725.27 & $580.22-870.32$ & DMSIC $^{18}$ \\
$\quad$ Ivabradine & 6741.00 & $5392.80-8089.20$ & Royal Gazette $^{20}$ \\
Cost of hospitalization & $56,552.27$ & $1152.69-626,058.00$ & Siriraj Hospital \\
\hline Utility & & & Adena, et al $^{10}$ \\
Stable HFrEF & 0.75 & $0.65-0.85$ & Adena, et al $^{10}$ \\
Hospitalization & 0.65 & $0.55-0.75$ & \\
\hline
\end{tabular}

Abbreviations: DMSIC, Drug and Medical Supply Information Center; THB, Thai baht; HFrEF; heart failure with reduced ejection fraction.

readmission and the risk of all-cause readmission in the standard group (Table 1).

\section{Costs}

Since this study was designed and conducted from a Thai healthcare system perspective, only direct medical costs, such as the costs of medications and hospitalization, were included. Other direct costs, like outpatient visits and laboratory investigations were assumed to be the same in both groups; hence, they were not included in the analysis. The acquisition cost of ivabradine, which was obtained from the Drug and Medical Supply Information Center (DMSIC) of the Thailand Ministry of Public Health, ${ }^{18}$ was 6741 THB per cycle or 74.9 THB per day. Cost of standard treatment was calculated from the unit cost of the representative medication and its proportion of usage, as mentioned above. The median price of a particular medication was used as the unit cost according to the recommendation of the Thai HTA guideline. ${ }^{19}$ Those median costs were obtained from the announcement of median drug price in accordance with the National Drug System Development Committee. ${ }^{20}$ Cost of standard treatment was 725.27 THB per cycle or 24.2 THB per day. The cost of hospitalization was obtained from the institutional database of Siriraj Hospital, which is Thailand's largest universityaffiliated tertiary referral center. The average hospital cost was 56,552.27 THB. All cost data were adjusted and presented as 2018 values, and were converted into United States dollars (USD) using an exchange rate of $32.88 \mathrm{THB} / \mathrm{USD} .^{22}$

\section{Utility}

Due to a paucity of preference-based health outcome data among HF patients in Thailand, the utility parameters were obtained from a cost-effectiveness study by Adena, et al. ${ }^{11}$ that measured utility by EuroQoL in patients enrolled in the SHIFT study. ${ }^{3,17}$ The utility of "stable HF health state" and "hospitalization health state" was 0.75 and 0.65 , respectively (Table 2 ).

\section{Study Analyses \\ Base-Case Analysis}

The base-case approach was used to estimate the ICER in THB per life year (LY) or QALY gained as the difference in total costs divided by the difference in outcomes of ivabradine plus standard treatment and standard treatment alone. According to the Thai Health Technology Assessment (HTA) guideline, ${ }^{21}$ lifetime costs and outcomes are to be discounted at an annual rate of $3 \%$. A new treatment was considered to be cost-effective when the estimated ICER was not greater than the threshold of 160,000 THB per

Table 3 Base-Case Results

\begin{tabular}{|c|c|c|}
\hline Variables & Ivabradine & Standard \\
\hline \multicolumn{3}{|l|}{ Cohort population } \\
\hline Total cost (THB/USD) & $7|, 07|(2,|6| .54)$ & $18,736(569.82)$ \\
\hline Life-years (years) & 8.14 & 7.92 \\
\hline QALYs (years) & 6.08 & 5.84 \\
\hline \multicolumn{3}{|l|}{$\begin{array}{l}\text { Incremental cost-effectiveness } \\
\text { ratio }\end{array}$} \\
\hline THB/life-year (USD/life-year) & $240,132(7,303.30)$ & \\
\hline THB/QALY (USD/QALY) & $214,219(6,515.16)$ & \\
\hline \multicolumn{3}{|l|}{$\begin{array}{l}\text { Subgroup analysis for patients } \\
\text { with } H R \geq 77 \mathrm{bpm}\end{array}$} \\
\hline Total cost (THB/USD) & $69,627(2,117.61)$ & I7,207 (523.33) \\
\hline Life-years (years) & 8.05 & 7.25 \\
\hline QALYs & 5.96 & 5.35 \\
\hline \multicolumn{3}{|l|}{$\begin{array}{l}\text { Incremental cost-effectiveness } \\
\text { ratio }\end{array}$} \\
\hline THB/life-year (USD/life-year) & \multicolumn{2}{|l|}{$65,690(1,997.88)$} \\
\hline THB/QALY (USD/QALY) & \multicolumn{2}{|l|}{$86,317(2,625.20)$} \\
\hline
\end{tabular}

Abbreviations: bpm, beats per minute; QALYs, quality-adjusted life-years; THB, Thai baht; USD United States dollars. 
QALY, or about 1.2 times per capita gross national income (GNI). ${ }^{22}$ Subgroup analysis in patients with a baseline heart rate $\geq 77 \mathrm{bpm}$ was also performed.

\section{Sensitivity Analysis}

The impact of altering each of the individual input parameters within its range was evaluated using one-way sensitivity analysis to test the robustness of the model results. Evaluated parameters included, but are not limited to, $\mathrm{CV}$ mortality, hospitalization, and readmission risk. According to the Thai HTA guideline, ${ }^{21}$ the discount rates varied from $0 \%$ to $6 \%$. In cases where no specific ranges are reported, drug costs are to be varied by $\pm 20 \%$, transitional probabilities are to be varied by $\pm 10 \%$, and

\section{A}

Incremental cost-effectiveness ratio (THB/QALY)

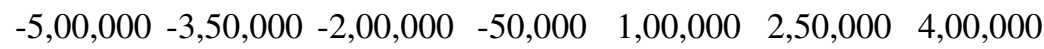

Risk of CV non-hospitalization death, Ivabradine (0.0140-0.0188)

Risk of CV non-hospitalization death, Standard (0.0154-0.0204)

Cost of HF hospitalization (1152.69-626058)

Cost of ivabradine (5392.80-8089.20)

Utility of stable HFrEF (0.65-0.85)

Lower value

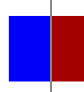

Upper value

Discount rate $(0-6 \%)$

B

$$
\begin{array}{lllllll}
-2,40,000 & -1,60,000 & -80,000 & 0 & 80,000 & 1,60,000 & 2,40,000
\end{array}
$$

Risk of CV non-hospitalization death, Standard (0.0154$0.0204)$

Risk of CV non-hospitalization death, Ivabradine (0.0140-0.0188)

Cost of ivabradine $(5,392.80-8,089.20)$

Cost of HF hospitalization $(1,152.69-626,058)$

Utility of stable HFrEF (0.65-0.85)

- Lower value

- Upper value

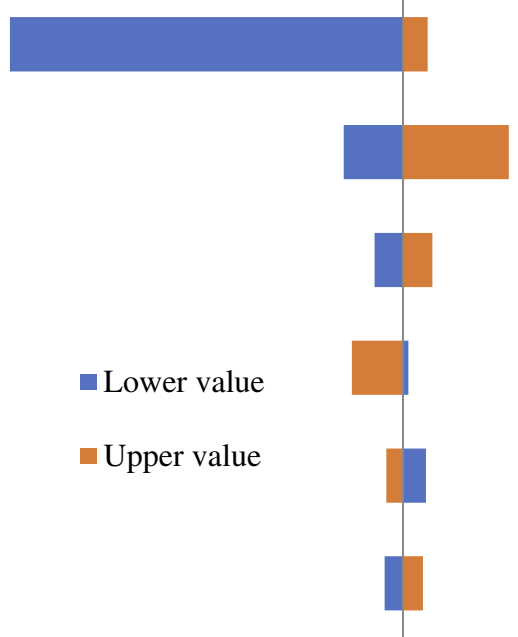

Discount rate $(0-6 \%)$

Figure 2 Tornado diagram of ivabradine plus standard treatment compared with standard treatment alone. (A) Cohort population. (B) Subgroup population with baseline $H R \geq 77$ bpm.

Abbreviations: CV, cardiovascular; HF, heart failure; HFrEF, heart failure with reduced ejection fraction; HR, heart rate; QALY, quality-adjusted life-year; THB, Thai baht. 
hospitalization costs are to be varied according to the minimum and maximum value. The results of one-way sensitivity analysis are demonstrated as a tornado diagram.

A probabilistic sensitivity analysis (PSA) was used to estimate overall parameter uncertainty in a model by varying all inputs sampled from the statistical distribution. ${ }^{23} \mathrm{~A}$ beta distribution was used for the probability and utility parameters, and a gamma distribution was used for the cost parameters. A log-normal distribution was assigned for the relative risk parameters. The process was repeated one thousand iterations, each ICER was recalculated from the resampled inputs simultaneously, and all ICERs were plotted on the cost-effectiveness plane. A cost-effectiveness acceptability curve (CEAC) was generated to demonstrate the likelihood of ivabradine costeffectiveness at different willingness to pay values. ${ }^{24}$

\section{Results \\ Base-Case Analysis}

The findings of this study revealed ivabradine plus standard treatment to be associated with higher cost and better health outcomes than standard treatment alone. The total cost of ivabradine plus standard treatment was 71,071 THB $(2,161.54$ USD) compared to a total cost of standard treatment alone of 18,736 THB (569.82 USD). Effectiveness measured as life-years (LYs) and quality-adjusted life-years (QALYs) was greater in the ivabradine plus standard treatment group than in the standard treatment group (8.14 vs $7.92 \mathrm{LYs}$ and 6.08 vs 5.84 QALYs, both, respectively). These values yielded ICERs of 240,132 THB/LY (7,303 $\mathrm{USD} / \mathrm{LY})$ and 214,219 THB/QALY (6,515.16 USD/ QALY), both of which are far higher than the Thai willingness to pay (WTP) threshold of 160,000 THB/QALY or 4,866.18 USD/QALY (Table 3).

The findings from subgroup analysis indicated the addition of ivabradine to standard treatment in HFrEF patients with baseline $H R \geq 77$ bpm to be a cost-effective treatment strategy. The resulting ICERs were 65,690 THB/LY (1,997.88 USD/ LY) and 86,317 THB/QALY (2,625.20 USD/QALY), which are both far lower than the Thai WTP threshold (Table 3).

\section{Sensitivity Analysis}

From 14 variables that varied within their respective specified range, we found that risk of non-hospitalization cardiovascular death, costs of hospitalization and ivabradine, utility of stable HF states, and discount rate had some impact on ICER in both cohort population analysis and subgroup population analysis, as shown in Figure 2A and B, respectively.

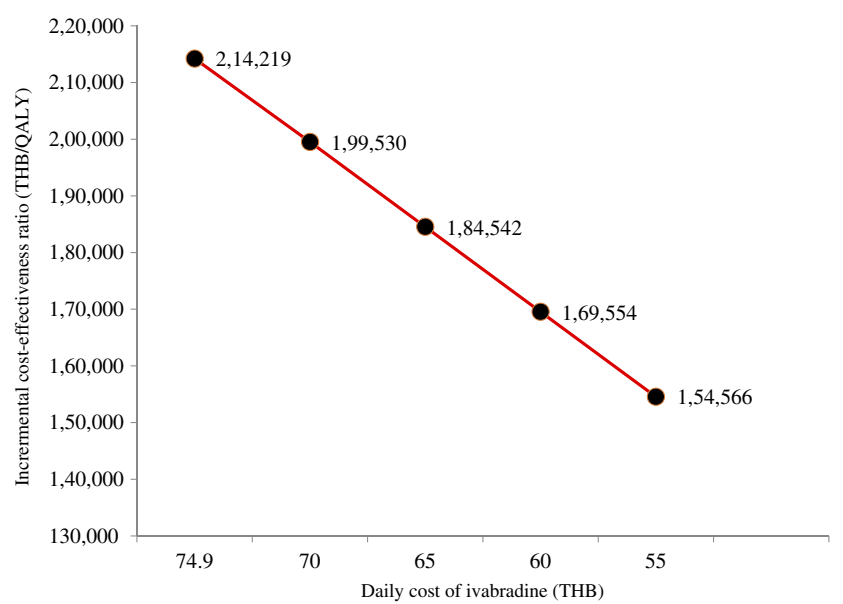

Figure 3 Analysis of the incremental cost-effectiveness ratio relative to changes in the daily cost of ivabradine.

Abbreviations: QALY, quality-adjusted life-year; THB, Thai baht.

The cost of ivabradine was varied to analyze the appropriate drug cost which yielded an ICER below the Thai threshold. The daily cost of ivabradine was estimated to decrease to approximately $56 \mathrm{THB}$ to bring the ICER below the WTP threshold of 160,000 THB/QALY (Figure 3).

As revealed from the scatterplots in Figure 4, ivabradine treatment had higher cost, but it produced better QALY in both cohort population and subgroup population (Figure 4). At a willingness to pay (WTP) level of 160,000 THB/QALY, the likelihood of ivabradine treatment being cost-effective was $46 \%$ in the cohort population, and $60 \%$ in the subgroup population (Figure 5).

\section{Discussion}

The base-case analysis in this study revealed that ivabradine plus standard treatment costs more than standard treatment alone, but that ivabradine treatment results in a greater number of QALYs in HFrEF patients aged $\geq 60$ years. However, the ICER was found to be above the Thai WTP threshold of $160,000 \mathrm{THB} / \mathrm{QALY}$, which indicates that ivabradine is not a cost-effective treatment strategy in this cohort population. However, our subgroup analysis revealed the addition of ivabradine to standard treatment in HFrEF patients with a baseline heart rate $\geq 77 \mathrm{bpm}$ to be a cost-effective treatment alternative, because its cost (ICER $=86,317 \mathrm{THB} / \mathrm{QALY}$ or 2625.20 USD/QALY) fell below the Thai WTP threshold of 160,000 THB/QALY. Findings from the United States, 25 United Kingdom, ${ }^{8}$ Greece, ${ }^{9}$ and Australia ${ }^{10}$ also revealed the cost-effectiveness of adding ivabradine to standard treatment in HFrEF patients with a baseline heart rate of $>70,75$, 75 , and $77 \mathrm{bpm}$, respectively, based on each country's respective acceptable WTP threshold. 

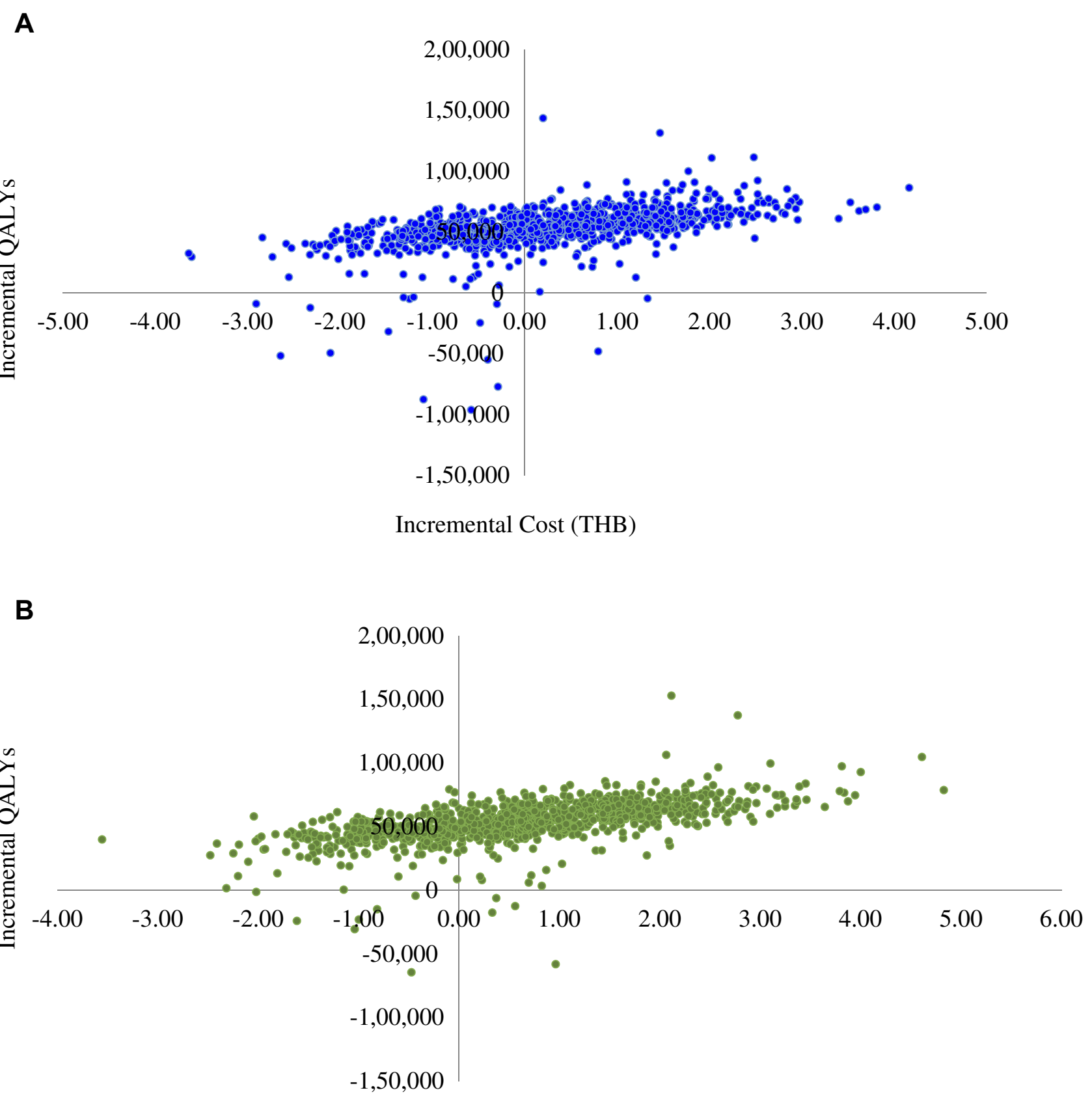

Incremental cost (THB)

Figure 4 Scatter plots of 1000 iterations for ivabradine plus standard treatment compared with standard treatment alone on a cost-effectiveness plane. (A) Cohort population. (B) Subgroup population with baseline HR $\geq 77$ bpm.

Abbreviations: bpm, beats per minute; HR, heart rate; QALY, quality-adjusted life-year; THB, Thai baht.

All of the studies referred to in this report that compared the cost-effectiveness between the two investigated treatments used treatment efficacy data from the SHIFT trial. $^{3}$ That trial demonstrated a significant reduction in the composite endpoint "cardiovascular death and hospitalization for worsening heart failure" (HR: 0.82, 95\% CI: 0.75 to 0.90 ) when ivabradine was added to the standard treatment. Despite the presence of several study-related differences among the participating countries that resulted in different estimated ICERs, none of the individual ICERs was above that country's WTP threshold. The aforementioned differences among countries included differences in the analytical decision models, the time horizons, the study perspectives, and the discount rates. 


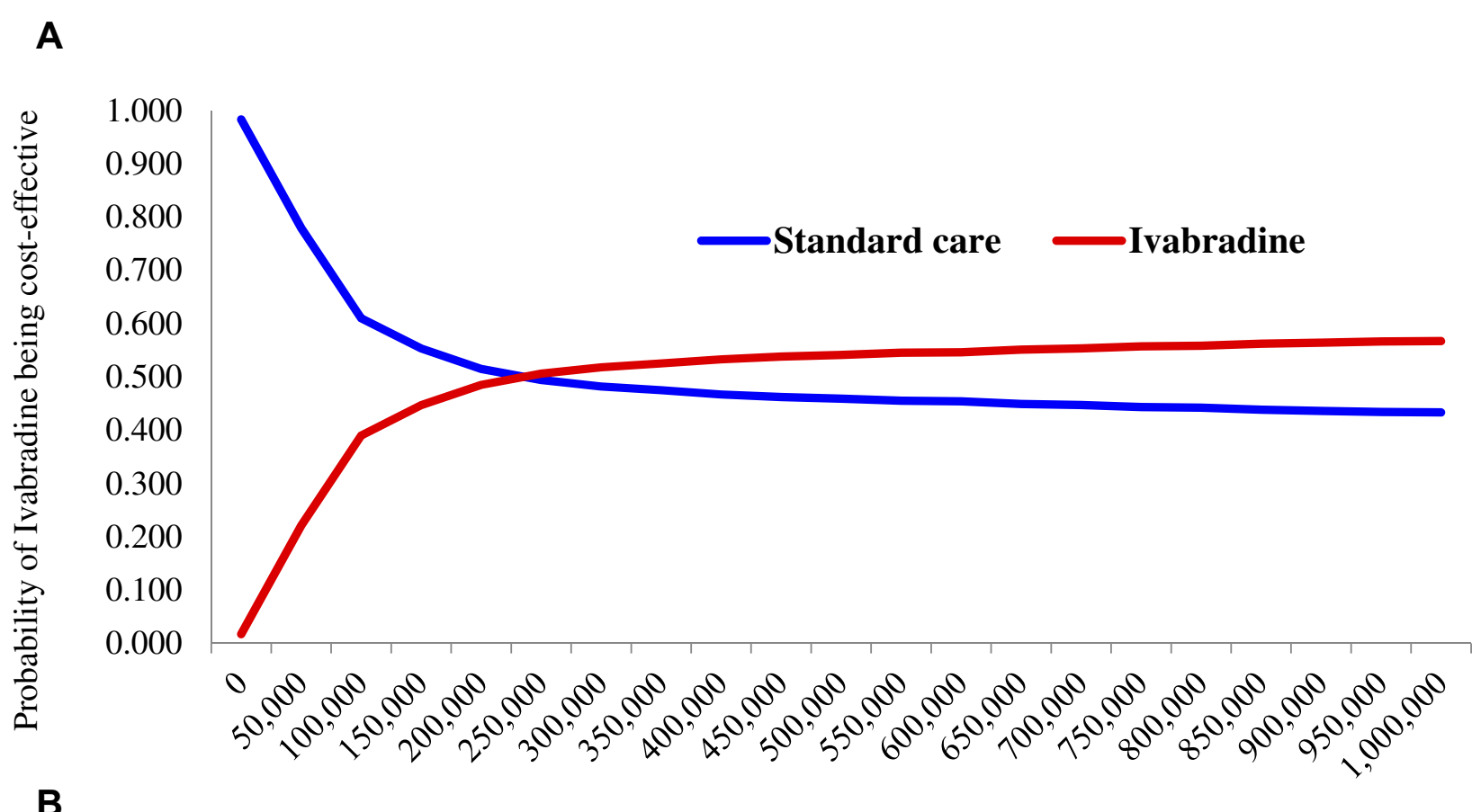

B

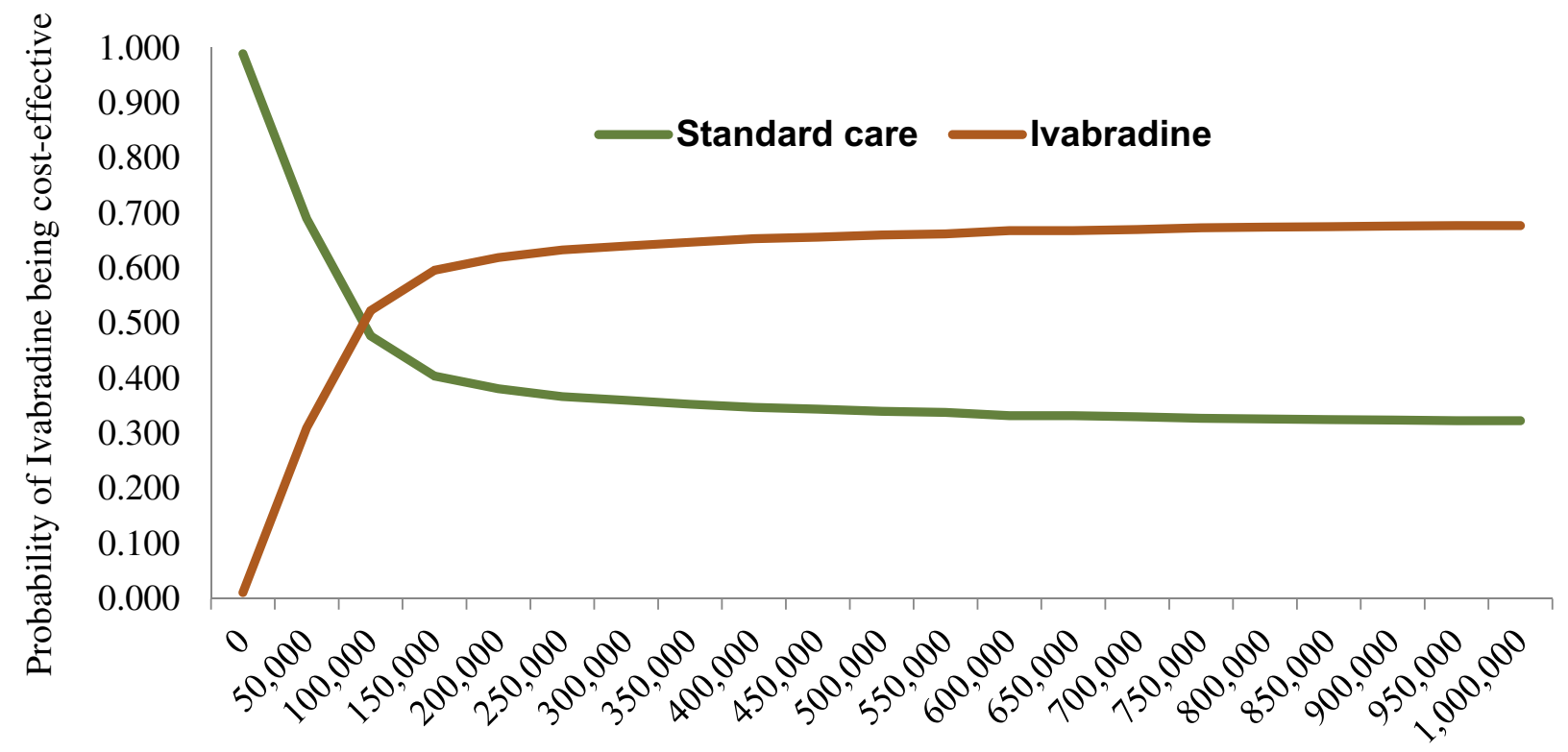

Figure 5 Cost-effectiveness acceptability curve of ivabradine plus standard treatment compared with standard treatment alone. (A) Cohort population. (B) Subgroup population with baseline HR $\geq 77 \mathrm{bpm}$.

Abbreviations: bpm, beats per minute; HR, heart rate; QALY, quality-adjusted life-year; THB, Thai baht.

Given the limited generalizability of findings from costeffectiveness studies conducted in other countries to a Thai context, we used Thailand-specific cost and epidemiological data in this study. Cardiovascular mortality and noncardiovascular mortality were based on the national trend of hospitalized heart failure patients in Thailand, ${ }^{13}$ the burden of disease in Thailand, ${ }^{15}$ and health statistics from the Thailand Ministry of Public Health. ${ }^{16}$ Hospitalization cost data were obtained from a large national tertiary referral hospital that provides both basic and advanced treatment to HF patients. We, therefore, assumed that these data would correctly reflect the cost of HF hospitalization in Thailand. The findings of oneway sensitivity analysis (Figure 2) revealed that the costs of HF hospitalization and ivabradine exerted some effect on the ICERs of both the cohort population and the subgroup population. A reduction in these costs would bring the ICERs in both 
groups down. If the daily cost of ivabradine could be reduced to approximately $56 \mathrm{THB}$, the ICER would be below the WTP threshold of 160,000 THB/QALY in the cohort population. At a daily cost for ivabradine of 56 THB and a WTP threshold of $160,000 \mathrm{THB} / \mathrm{QALY}$, the cost-effectiveness of the addition of ivabradine to standard treatment would be $46 \%$ in the cohort population, and $60 \%$ in the subgroup population.

\section{Conclusion}

The results of this study revealed the addition of ivabradine to standard treatment to be a cost-effective treatment strategy in Thai HFrEF patients with abaseline heart rate $\geq 77 \mathrm{bpm}$.

\section{Disclosure}

The authors report no conflicts of interest in this work.

\section{References}

1. Ponikowski P, Voors AA, Anker SD, et al. 2016 ESC guidelines for the diagnosis and treatment of acute and chronic heart failure: the Task Force for the diagnosis and treatment of acute and chronic heart failure of the European Society of Cardiology (ESC) developed with the special contribution of the Heart Failure Association (HFA) of the ESC. Eur Heart J. 2016;37(27):2129-2200. doi:10.1093/eurheartj/ehw128

2. Yancy CW, Jessup M, Bozkurt B, et al. 2017 ACC/AHA/HFSA focused update of the $2013 \mathrm{ACCF} / \mathrm{AHA}$ guideline for the management of heart failure: a report of the American College of Cardiology/ American Heart Association Task Force on Clinical Practice Guidelines and the Heart Failure Society of America. J Am Coll Cardiol. 2017;70(6):776-803. doi:10.1016/j.jacc.2017.04.025

3. Swedberg K, Komajda M, Bohm M, et al. Ivabradine and outcomes in chronic heart failure (SHIFT): a randomised placebo-controlled study. Lancet. 2010;376(9744):875-885. doi:10.1016/S0140-6736(10)61198-1

4. DiFrancesco D. Funny channels in the control of cardiac rhythm and mode of action of selective blockers. Pharmacol Res. 2006;53 (5):399-406. doi:10.1016/j.phrs.2006.03.006

5. Pocock SJ, Wang D, Pfeffer MA, et al. Predictors of mortality and morbidity in patients with chronic heart failure. Eur Heart J. 2006;27 (1):65-75. doi:10.1093/eurheartj/ehi555

6. Fox K, Ford I, Steg PG, et al. Heart rate as a prognostic risk factor in patients with coronary artery disease and left-ventricular systolic dysfunction (BEAUTIFUL): a subgroup analysis of a randomised controlled trial. Lancet. 2008;372(9641):817-821. doi:10.1016/S0140-6736(08)61171-X

7. Flannery G, Gehrig-Mills R, Billah B, Krum H. Analysis of randomized controlled trials on the effect of magnitude of heart rate reduction on clinical outcomes in patients with systolic chronic heart failure receiving beta-blockers. Am J Cardiol. 2008;101(6):865-869. doi:10.1016/j.amjcard.2007.11.023

8. Griffiths A, Paracha N, Davies A, Branscombe N, Cowie MR, Sculpher M. The cost effectiveness of ivabradine in the treatment of chronic heart failure from the UK national health service perspective. Heart. 2014;100:1031-1036. doi:10.1136/heartjnl-2013-304598
9. Kourlaba G, Parissis J, Karavidas A, et al. Economic evaluation of ivabradine in the treatment of chronic heart failure in Greece. BMC Health Serv Res. 2014;14:631. doi:10.1186/s12913-014-06 31-0

10. Adena MA, Hamann G, Sindone AP. Cost-effectiveness of ivabradine in the treatment of chronic heart failure. Heart Lung Circ. 2018: $28 ; 1-9$.

11. Krittayaphong R, Permsuwan U. Cost-effectiveness analysis of sacubitril-valsartan compared with enalapril in patients with heart failure with reduced ejection fraction in Thailand. Am J Cardiovasc Drugs. 2018:18(5);1-9.

12. Tanvejsilp P, Ngorsuraches S. Defining the scope of health technology assessment and types of health economic evaluation. $J$ Med Assoc Thai. 2014;97(Suppl 5):S10-6.

13. Janwanishstaporn $\mathrm{S}$. National trend, in-hospital and long term outcomes in the hospitalized heart failure patients in Thailand. Thai Heart J. 2015;28:128.

14. Krum H, Sindone A. Significant reduction in all-cause mortality with ivabradine in chronic heart failure patients with baseline heart rate $\geq 77 \mathrm{bpm}$ : subgroup analysis of SHIFT. Heart Lung Circ. 2013;22(Suppl 1):S87-S88. doi:10.1016/j.hlc.2013.05.208

15. Bundhamcharoen K, Aungkulanon S. Burden of disease in Thai population 2009. Int Health Policy Program. 2012.

16. Health Statistics Strategy and Planning Division, Ministry of Public Health. Mortality rate per 100,000 Thai population by causes of death during 1998-2016; 2016 [updated July 10, 2018]. Available from: http://social.nesdb.go.th/SocialStat/ StatReport_Final.asp $x$ ?reportid $=441 \&$ template $=2 \mathrm{R} 1 \mathrm{C} \&$ yeartype $=$ M\&subcatid $=15$.

17. Komajda M, Tavazzi L, Swedberg K, et al. Chronic exposure to ivabradine reduces readmissions in the vulnerable phase after hospitalization for worsening systolic heart failure: a post-hoc analysis of SHIFT. Eur J Heart Fail. 2016;18:1182-1189. doi: $10.1002 /$ ejhf.582

18. Drug and Medical Supply Information Center, Ministry of Public Health; 2018 [updated July 12, 2018]. Available from: http://dmsic. moph.go.th.

19. Riewpaiboon A. Measurement of costs for health economic evaluation. J Med Assoc Thai. 2014;97(Suppl 5):S17-26.

20. National Drug System Development Committee. Medium Drug Price Announcement. Bangkok: Royal Gazette in Thailand; 2018.

21. Permsuwan U, Guntawongwan K, Buddhawongsa P. Handling time in economic evaluation studies. J Med Assoc Thai. 2014;97(Suppl 5): S50-S58.

22. Limwattananon S. Sensitivity analysis for handling uncertainty in an economic evaluation. In: Chaikledkaew U, Teerawattananon Y, editors. Guidelines for Health Technology Assessment in Thailand. 2nd ed. Nonthaburi: Wacharin; 2013:105-119.

23. Briggs AH. Handling uncertainty in cost-effectiveness models. Pharmacoeconomics. 2000;17(5):479-500. doi:10.2165/00019053200017050-00006

24. Zethraeus N, Johannesson M, Jönsson B, Löthgren M, Tambour M. Advantages of using the net-benefit approach for analysing uncertainty in economic evaluation studies. Pharmacoeconomics. 2003;21(1):39-48. doi:10.2165/00019053-200321010-00003

25. Kansal AR, Cowie MR, Kielhorn A, et al. Cost-effectiveness of ivabradine for heart failure in the United States. $J$ Am Heart Assoc. 2016;5:e03221. doi:10.1161/JAHA.116.003221 


\section{Publish your work in this journal}

ClinicoEconomics and Outcomes Research is an international, peerreviewed open-access journal focusing on Health Technology Assessment, Pharmacoeconomics and Outcomes Research in the areas of diagnosis, medical devices, and clinical, surgical and pharmacological intervention. The economic impact of health policy and health systems

organization also constitute important areas of coverage. The manuscript management system is completely online and includes a very quick and fair peer-review system, which is all easy to use. Visit http://www.dovepress.com/testimonials.php to read real quotes from published authors.

Submit your manuscript here: https://www.dovepress.com/clinicoeconomics-and-outcomes-research-journal 